\title{
Practice theories and supply chain sustainability: a systematic literature review and a research agenda
}

\author{
Minelle E. Silva and Morgane M.C. Fritz \\ Department of Supply Chain, Purchasing and Project Management CERIIM, \\ Excelia Business School, La Rochelle, France, and \\ Wael Hassan El-Garaihy \\ Imam Abdulrahman Bin Faisal University, Dammam, Saudi Arabia
}

Received 29 January 2021

\begin{abstract}
Purpose - This paper presents an investigation into the ways the term "practice" is commonly referenced in supply chain management academic papers. Scholars have not yet developed a common understanding of the meaning and do not use practice theories when examining practices related to sustainability management in supply chains. Hence, the authors highlight theoretical gaps and make recommendations for future research.

Design/methodology/approach - Grounded in a systematic literature review of 232 peer-reviewed papers published in operations and supply chain management journals, a qualitative content analysis was conducted using both a deductive and an inductive approach.

Findings - Results show that supply chain sustainability (SCS) scholars seem barely interested in increasing the understanding of the term "practice," widely used in the literature to refer to a practical context. Moreover, a clear distinction between being practical and using practice theories to study SCS practices is needed. A descriptive and critical analysis revealed eight key supply chain practices connected to sustainability, with a clear reflection on their meaning. As awareness of practice theories for research on SCS is limited, few recommendations for researchers and practitioners were identified.

Originality/value - Unlike prior literature reviews, the authors reinforce the need to increase the maturity of the SCS field by going beyond superficial theoretical building. Practice theories pathways are provided to enlighten scholars on how to avoid using the term "practice" as taken-for-granted and on how to deal with SCS research and practice.
\end{abstract}

Keywords Supply chain practices, Supply chain sustainability, Practice-based view, Practice-based studies, Practice theories, Systematic literature review

Paper type Research paper

\section{Introduction}

Supply chain sustainability (SCS) is a research field that over time has been associated with a high number of definitions (e.g. Dubey et al., 2017) and frameworks (Ansari and Kant, 2017). However, the theory-building process in the field has not kept pace with the evolution implied by these numbers (cf. Touboulic and Walker, 2015). To address this issue, scholars and practitioners need to begin using the same, or at least similar, terminology, which depends on a set of interests, understandings and deliveries from many sources. Thus, in this paper we explore how practice theories can be used as a theoretical lens of analysis in

(C) Minelle E. Silva, Morgane M.C. Fritz and Wael Hassan El-Garaihy. Published in Modern Supply Chain Research and Applications. Published by Emerald Publishing Limited. This article is published under the Creative Commons Attribution (CC BY 4.0) licence. Anyone may reproduce, distribute, translate and create derivative works of this article (for both commercial and non-commercial purposes), subject to full attribution to the original publication and authors. The full terms of this licence may be seen at http:// creativecommons.org/licences/by/4.0/legalcode.

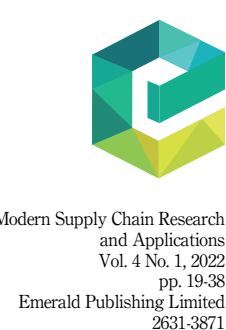

DOI 10.1108/MSCRA-01-2021-0001 
MSCRA

4,1

SCS research to ensure maturity of the field and improve the understanding of SCS practices.

We focus on the Practice Theories since these underexplored theories can support further implications in the supply chain management (SCM) field, as well as further theorization (e.g. Maletic et al., 2018; Silva and Figueiredo, 2020). Practice Theories are not yet well established in SCS studies; however, their use has been rising recently (e.g. Silva et al., 2018; Tiwari et al., 2020; Shaw et al., 2021). Thus, this literature review ground for a common research agenda to study practice theories. Indeed, in multiple journal articles, the term "practice" is used according to its taken-for-granted meaning in a very broad sense (i.e. lato sensu) without mentioning the specific meaning of the term as it is theoretically defined within practice theories (i.e. stricto sensu). To establish close interactions with other stakeholders, scholars should agree on both the meaning and the evaluation of "practice" (Hong et al., 2018). For instance, currently the phrase "supply chain practice" is linked to discussions related to actions/initiatives/issues when focusing on the daily operations of companies worldwide, but it also refers to indicators/factors/items (e.g. Kusi-Sarpong et al., 2016) when used in quantitative research.

Despite the existence of dual interpretations, the lato sensu use of the term predominates, which increases the complexity of theorizing about SCS and deriving practical implications. We address this lack of rigor and contribute to the literature by studying a more consistent approach to the study of "practices" to refine and extend theory on SCM (Seuring et al., 2021). However, this paper is not intended to reveal mistakes in prior research, nor is it intended to speak as the authority on who is wrong and who is right; instead, this paper is intended to appeal to SCS scholars to understand and reflect on the need to clarify the meanings of relevant terminology to establish maturity for the field. This literature review aimed to encourage researchers to use practice theories when studying a set of activities in SCM that foster sustainability to clearly identify practices that support or hinder sustainability and, thus, derive clearer and useful practical and theoretical implications from their work.

Since SCM studies transitioned into a focus on sustainability more than one decade ago (e.g. Carter and Rogers, 2008; Seuring and Müller, 2008), it is time to strengthen and extend our use of theories in the field. To identify a practice, we need to understand not only what the activity is but also how, why and by whom it has been interpreted and employed since practice theories have no unified definition (Nicolini, 2012). In this sense, this research was intended to answer the following question: How can practice theories support sustainability management research in supply chains?

To answer this question, we developed a systematic literature review (Tranfield et al., 2003) of 232 articles published in top academic journals in the operations and SCM field. The analysis showed that researchers are barely interested in examining the connection between practices and SCs (e.g. Mejías et al., 2016; Subramanian and Gunasekaran, 2015). Our research was centered on "practice" from a stricto sensu point of view, i.e. following a theoretical approach, which refers to a set of actions (or activities in the SCM context) interacting with each other (Antonacopoulou, 2015) on both intra- and inter-organizational levels to facilitate performance and support decision-making processes (Bromiley and Rau, 2014). As such, this paper contributes (1) to informing a better understanding of SCS practices, which relies on a consensus among scholars to not only develop or use new terms but also to ensure the applicability of such terms; and (2) to explore two alternative theoretical approaches to studying SCS: practice-based studies (PBS) and practice-based view (PBV).

\section{Supply chain sustainability (SCS) practices}

Over time, the nature, configuration and understanding of SCM in theory and in practice have changed to address the new dynamics of society (Min et al., 2019), which, according to Min 
and colleagues, should consider different elements, including sustainability. However, this does not occur in a range of SCM studies that still do not consider sustainability as a crucial component of the supply network reality. As presented by different literature reviews in the field, although the understandings of strategies (e.g. Seuring and Müller, 2008), supplier selection (e.g. Rashidi et al., 2020), purchasing (e.g. Walker et al., 2012) and performance (e.g. Subramanian and Gunasekaran, 2015) have evolved, by applying sustainability arguments, the SCM literature continues to reproduce confusion, mainly through incorporating green, social and sustainable terms into the relationship. The purpose of the research in focus in this paper was to reduce this confusion by supporting further maturity in the SCS field. Ahi and Searcy (2013), for example, discovered multiple concepts in the definition of green and sustainable SCM, reflecting a situation that sometimes results from the use of a term in an unexpected way.

Studies have been conducted that focused on green SCM (e.g. Geng et al., 2017; Graham, 2018) and social SCM (e.g. Mani and Gunasekaran, 2018; Zhu et al., 2016); however, in discussions on sustainability, a gap seems to exist in the main comprehension of the SCS terminology. In 2011, Carter and Easton discovered an overlap in meaning regarding the use of "sustainability" and "environmental sustainability," but approaching the social side of sustainability still has limitations (Carter et al., 2019). Often papers mention a focus on the triple bottom line (TBL) perspective to explain sustainable SCM (e.g. Pagell and Wu, 2009; Seuring and Müller, 2008), but that does not clarify what constitutes sustainable SCM, which indicates the need to reflect on what sustainability means in the SC context. For instance, Fritz and Silva (2018) reflected on the applicability of the TBL as a limited means for understanding the SCS concept, which can invite opportunities to add other meanings, such as sustainable development goals.

SCS research increased in the years during which focus was placed on three major concerns. A first concern related to measures and techniques that companies have taken to reduce their impacts on the environment (e.g. Pagell and Shevchenko, 2014; Schrettle et al., 2014; Subramanian and Gunasekaran, 2015). Second, the strategies companies have followed to engage their SC stakeholders beyond the firm and suppliers have been addressed (e.g. Seuring and Müller, 2008; Carmagnac, 2021). And third, studies interested in improving SC sustainability performance (e.g. Kogg and Mont, 2012). However, the meaning of SCS is narrowly based on a set of studies that do not explain how to move from an instrumental approach (Gold and Schleper, 2017) to what we call an "organic approach," i.e. a perspective assuming both similarities and singularities of SC configurations and contexts.

Amid these reflections, searching for information about performance results may not be all that is needed; a practice-based perspective may also be necessary for sustainability. The term "SCS practices" is widely used in the literature with diverse targets. In this paper, SCS is considered to refer to "the specific managerial actions [represented here by a set of SCM activities] that are taken to make the supply chain more sustainable with an end goal of creating a truly sustainable chain" (Pagell and Wu, 2009, p. 38). By following this definition, this paper encourages a reflection on the roots and consequences of such SCS practices in managing SC relationships, which deserves further attention. The following section provides an overview of the main approaches to examining "practice" employed in the SCM literature to further explore the lack of studies in the field.

\subsection{Highlighting contributions from practice theories}

Practice theories constitute a family of theoretical approaches that help scholars to study daily actions (Nicolini, 2012). In this context, as argued by Nicolini (2012), there is not $a$ practice theory, but a set of theoretical reflections without any unified theory. These theories are applied to different disciplines and the SCS literature has received increasing attention 
MSCRA 4,1

from practice theories, including the PBV (e.g. Bag et al., 2021; Kosmol et al., 2019; Silva et al., 2018) and PBS (e.g. Silva and Figueiredo, 2020). The use of practice theories, which emanates from multiple backgrounds (Gherardi, 2009), should consider those elements that are clearly evident, as well as those hidden from inattentive eyes. Prior research has included definitions of "practice" and its customary and habitual characteristics but without exploring the real meaning of such definitions as they are applied by practitioners (e.g. Oxford Dictionary, 2013 cited in Beske and Seuring, 2014). In this context, Beske and Seuring (2014) used the concept of practice to focus on performance improvement (cf. Flynn et al., 1995), which is not an indication that an effective use of the term "practice" exists, since it seems to assume a secondary role. In fact, if (management) practices are part of SCM, they need to be understood separately, with meaning, relevance and applicability.

Within this understanding, despite initial interest in the field, it has long been recognized that in the context of (sustainable) logistics and SCM studies: (1) scholars are revealing little more than what exists in reality (Sweeney, 2012), (2) prescriptions for success (i.e. best practice), range in focus in a positive way (see Touboulic and McCarthy, 2019) and (3) scholars are more interested in trends in SCM than in the "practice" (Min et al., 2019), which may limit its understanding. Similar to Sweeney (2012), we question the use of "best practice" because it seems to imply the existence of one single optimum scenario. Such questioning is necessary because, in the process of adding or creating best practices for sustainability (cf. Mejías et al., 2016), one important question should emerge - "best practices" for whom (Touboulic and McCarthy, 2019)?- - because we need to understand who carries out the sustainability practice (Silva and Figueiredo, 2017). This reflection generates discussions on the applicability of best practice lists because the products, processes, people and cultures of each company are unique to that company (Sweeney, 2012), which means implementing the same "practice" every time, everywhere, for everyone may not be feasible.

We understand, then, that the role of practice theories is to provide a new theoretical lens through which to differentiate between SCS with a theoretical background (i.e. stricto sensu) and SCS with a practical background (i.e. lato sensu). Some questions and confusion may emerge about what constitutes practice in comparison to routine, capability, indicators and so on. We argue that these other concepts can support an understanding of practice, but with clear boundaries in theory and in reality, which increases the need to consider these topics in relation to practice theories. When looking for these co-existent concepts, we demonstrate a new maturity level for the field. We centered our discussion on two main avenues for research, namely, the PBV and PBS. These approaches are complex and can support scholars in their efforts to be more connected with practitioners, considering the essence of both perspectives. Following is our understanding of these two theoretical approaches:

(1) Practice-based view: We understand this approach to "practice" to refer to "a defined activity or set of activities that a variety of firms might execute" (Bromiley and Rau, 2014, p. 1249), in which activities in isolation do not make the best use of resources. Such a perspective has a direct relation with the resource-based view (Hitt et al., 2016; Silva et al., 2018). Applied to SCs, Carter et al. (2017) argued that the PBV may span dyads, triads and networks, which makes this view of "practice" more connected with strategic decisions and more focused on improving performance. Furthermore, the PBV can help explain differences in business performance for SCM and operations researchers (Bag et al., 2021) and provides a useful foundation for practitioners for making decisions on SC environmental strategies and performance measurements (Khan and Yu, 2020; Shaw et al., 2021; Silva et al., 2019).

(2) Practice-based studies: We understand this as part of the range of theories of practice (Gherardi, 2009) that are concerned with explaining what practice is and what it does 
and are more centered on studying the routinization of a new social order (Silva and Figueiredo, 2020). For Silva and Figueiredo (2020), PBS contributes to SCS because the studies facilitate explanations on the nature of sustainability and, at the same time, highlight the need to understand SC practices. In that context, multiple fields are affected by this approach, such as strategy-as-practice (Jarzabkowski, 2004) and organizational learning (Gherardi, 2001). Research opportunities that use such a perspective to explore SCM and operations issues are plentiful.

These concepts have their own roots and reflections, so when using such approaches, we need to understand their theoretical and epistemological backgrounds to advance our comprehension of SCS practices. According to Antonacopoulou (2015), the concept of practice adds value to companies in connecting operational and strategic priorities, which can happen through business units, functional teams or working groups. In such cases, the "practice" fits with SCM mainly because one of the issues for SC managers is value creation among their members/stakeholders (Min et al., 2019), and at the same time, practice supports the recognition of explanations of reality that should not be limited to its reduction but, instead, include its complexity. The use of practice approaches highlights the role of researchers in co-producing knowledge with practitioners and in deriving practical implications of their research, which is still to be improved (Marabelli and Vaast, 2020).

\section{Research method}

To understand how practice theories can support SCS research, the method used in this study was a structured literature review based on Fink (2014) and Tranfield et al. (2003). This method was chosen because it allows for an analysis of a wide range of reference documents - in this case, academic publications - to identify the state-of-the-art in a specific domain, as well as contradictions or common grounds that justify the need for further research and that support the refinement and extension of theory in SCM (Seuring et al., 2021). A structured literature review (see Figure 1) has the advantage of being a reproducible method because it consists of clear steps (Seuring and Gold, 2012).

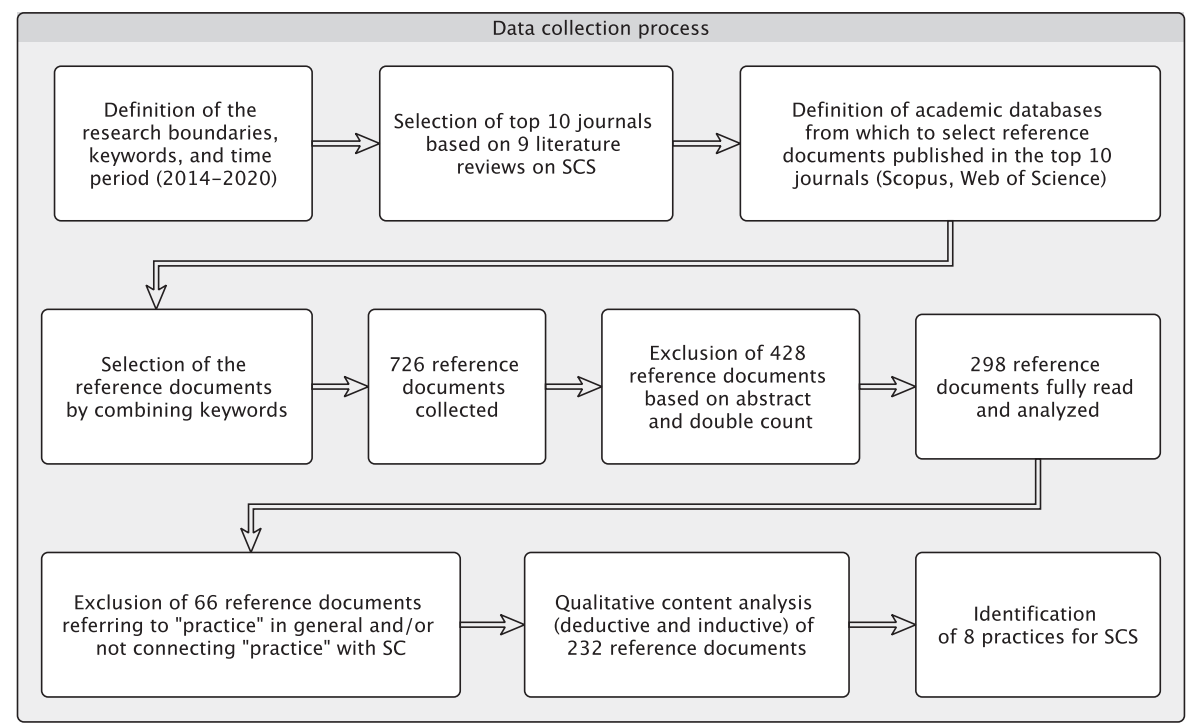

Figure 1.

Structured literature review process 
MSCRA

4,1

Since this research was focused on identifying how the term "practice" is used in the SCS literature, the research boundary established was academic journals focusing on SCM or publishing research on SCS that used the terms "practice" and "sustainability." The search period was set between 2014 and 2020 to reflect on seven full years of research in the domain. We selected this period based on Touboulic and Walker (2015), who developed a structured literature review focused on SCS theories with a timespan that ended in 2013, at which time practice theories had not yet been identified as being used in the field. Hence, we can consider that before 2013, no research on SCM had used practice theories. Using this reference prompted our decision to include almost a decade evolution of publications (2014-2020). Two databases were chosen due to their clear link with management, SCs and operations: Scopus and Web of Science. In these databases, we searched for articles published in the journals that contributed most to the field. We defined these journals by looking at nine published literature reviews on SCS over the defined period because they clearly document the number of articles published on SCS per journal (see Appendix A).

We compared these nine lists of top journals to identify which journals were mentioned in at least four reviews in order to define our own list of journals. This process elicited 10 journals as the most relevant in the field. From these 10 journals, we then extracted articles that contained the terms "practice" and "sustainability," as previously mentioned. However, to ensure that we included all relevant publications based on our research parameters, a range of words were used. For example, to identify publications referring to a "practice," we realized that it would be limited to focus only on this term, since sometimes authors may use other terms, such as "tool," to refer to a practice. Because practice is understood as a set of activities, as noted, we needed to also consider synonymous terms for these activities. Hence, we used the following keywords: ("sustainab*" OR "environmental" OR "green" OR "social" OR "CSR") AND ("practice" OR "performance measurement" OR "performance management" OR "tool") AND ("supply chain management" OR "supply chain" OR "supply chain practice"). This search produced a total of 726 articles.

These 726 articles were screened by the first two authors of this paper, each reviewing an equal share, as recommended by Tranfield et al. (2003), to avoid bias in the selection process. To retain articles fitting our research focus, we screened the data of the 726 articles and retained only those in which the word "practice" is used in connection with sustainability and/ or supply chains in the title, abstract or keywords. During this process, we used the following exclusion criteria: (1) duplication, (2) papers that refer only to best practices and (3) articles that mention "practice" in a very broad sense (i.e. lato sensu). This process led to the exclusion of 428 articles, leaving 298 to be analyzed.

Furthermore, we were interested in analyzing papers that contributed to identifying what SCS practices are, what frameworks are developed using "practice" according to its stricto sensu meaning, and what other theories are associated with research on SCS practices. Hence, we further analyzed all 298 articles by reading them and examining their content to extract the data we wanted to highlight in this literature review. All three authors were involved in this process, and the analysis done by each author was reviewed by at least one other author. This double-check process is relevant to ensuring the reliability of the data analysis and to providing transparency during the research analysis (Seuring and Gold, 2012).

Articles that were identified in this stage of the screening process that used the term "practice" only in a general way (e.g. "best practice," "good practice," "in practice") and/or that used the term "practice" but not in relation to SCs (e.g. "CSR practices," "practices of regulations," "cultivation practices") were excluded. Articles focusing on sustainability performance or sustainability assessment without linking it to the term "practice" and "supply chain" were also excluded, as were articles focusing on individual practices of specific populations (e.g. consumers). In total, an additional 66 papers were excluded based on 
the reading of the full text, leaving 232 articles to be analyzed to show the state-of-the-art in SC practice connected to sustainability management.

The qualitative content analysis approach used was based on the guidance of Elo and Kyngäs (2008) and was deductive and inductive. For the deductive stage, a grid developed for analysis helped the researchers to focus on specific information that we wanted to highlight in this literature review, which can be classified as follows: journal, year of publication, sustainability dimension, theories used, existence of a framework related to sustainability practices in SCs, industry sector, research design, data collection technique and data analysis methods. The grid is available upon request. These items were selected based on diverse literature reviews on SCS (e.g. Seuring and Müller, 2008; Touboulic and Walker, 2015). This detailed process has allowed us to assert the reliability, validity and replicability of the work performed. For the inductive stage, by following the concept that practices comprise a set of activities, we emphasized the highest number of activities that appeared in the selected papers. The selection of these activities through the lens of PBV and PBS helped us to recognize the main practices found in SCS studies. As presented in the findings section, we combined activities that were related to a specific SCS practice, which are incorporated into the final eight practices for SCS identified (see Table 1 and Figure 2). The final list of 232 articles is available in Appendix B.

\section{Results}

This structured literature review enabled us to identify the state-of-the-art literature on sustainability practice in SCM. Next, we provide some descriptive statistics and a critical reflection on the topic derived from our analysis to answer our research question.

\subsection{Descriptive analysis}

Table 2 summarizes the main descriptive information gathered. The analysis was conducted based on 232 papers published within a seven-year period (2014-2020); a significant increase in the number of relevant articles published over the course of these years can be observed until 2018. Journal of Cleaner Production (83 papers out of 232) and International Journal of Production Economics (36 papers out of 232) published the most articles relevant to the research focus, followed by Supply Chain Management (27/232), International Journal of Operations and Production Management (20/232), International Journal of Production Research (18/20), Business Strategy and the Environment (18/20), Journal of Purchasing and Supply Management (8/232), International Journal of Physical Distribution and Logistics Management (8/232), Journal of Business Ethics (8/232) and Journal of Supply Chain Management (6/232). These findings corroborate those of all literature reviews we used to select the journals to analyze (see method section).

Table 2 indicates that the number of studies in which the survey method was adopted (99 papers; $43 \%$ of total) is high; in comparison to the low percentage of articles with a theoretical approach $(3 \%)$ a significant lack of balance is highlighted. The choice of research design must be reflected upon with consideration of the need to use more aligned research designs, following the theory behind the topic. For instance, the use of the case study methodology (63 papers; $27 \%$ of total) as a qualitative approach has greater potential to demonstrate what practices are and how they are carried out in reality because case studies constitute an appropriate research design for answering "how" questions (Yin, 2014). Of course, methodology choice depends on the researcher's approach. The PBV allows the use of quantitative methods (cf. Bromiley and Rau, 2014); however, the PBV has received some criticism for not considering the nature of practices, for instance.

As depicted in Table 2 and $13 \%$ of the articles reviewed (30 out of 232) do not clearly explain the data collection techniques used, which demonstrates a lack of reliability. 


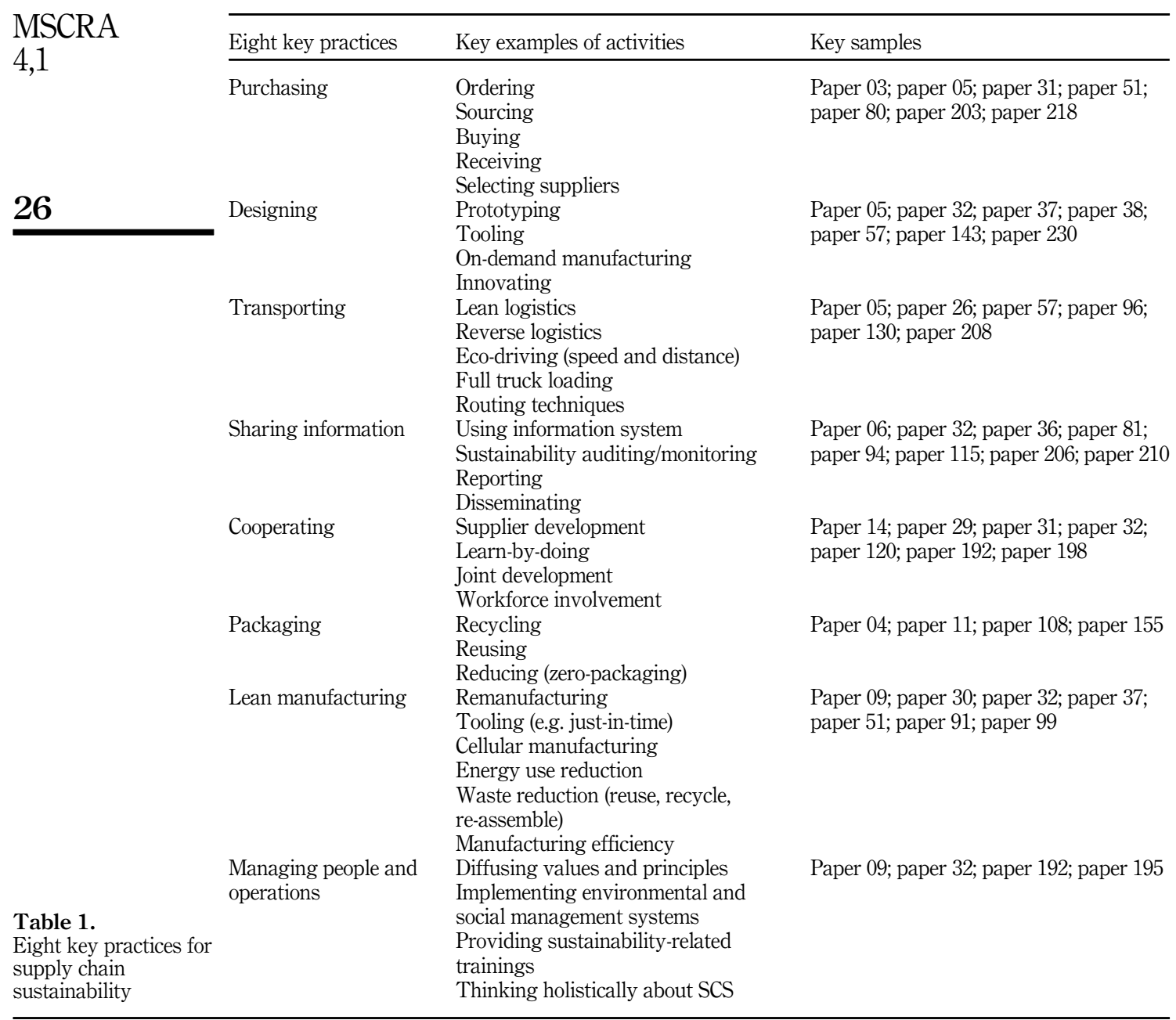

This may be related to a specific research design (e.g. modeling); however, the data collection techniques used should be clearly presented, especially for studies on practice. In terms of data analysis technique, the SCS body of research relied heavily on modeling, with 68 papers ( $29 \%$ of total) analyzed. Also, quantitative techniques (statistics) were used most frequently for data analysis, which is aligned with the number of questionnaires for data collection (90 out of 232). However, such findings show the need to use more qualitative research designs to contribute to defining and understanding sustainability practices in SCs.

Concerning sustainability dimensions, the environmental dimension was the most observed ( $38 \%$ of total), which is not surprising because a constant overlap can be found in the literature (Carter and Easton, 2011). In sequence, we uncovered a range of papers that mentioned TBL ( $25 \%$ of total) and mixed dimensions ( $20 \%$ of total); however, these papers do not clearly define sustainability or even outline the main talking points for discussion on the topic. They do, however, include a general mention, which prompts contemplation as to what constitutes the core of the research: Is the researcher really looking to identify SCS practices? 


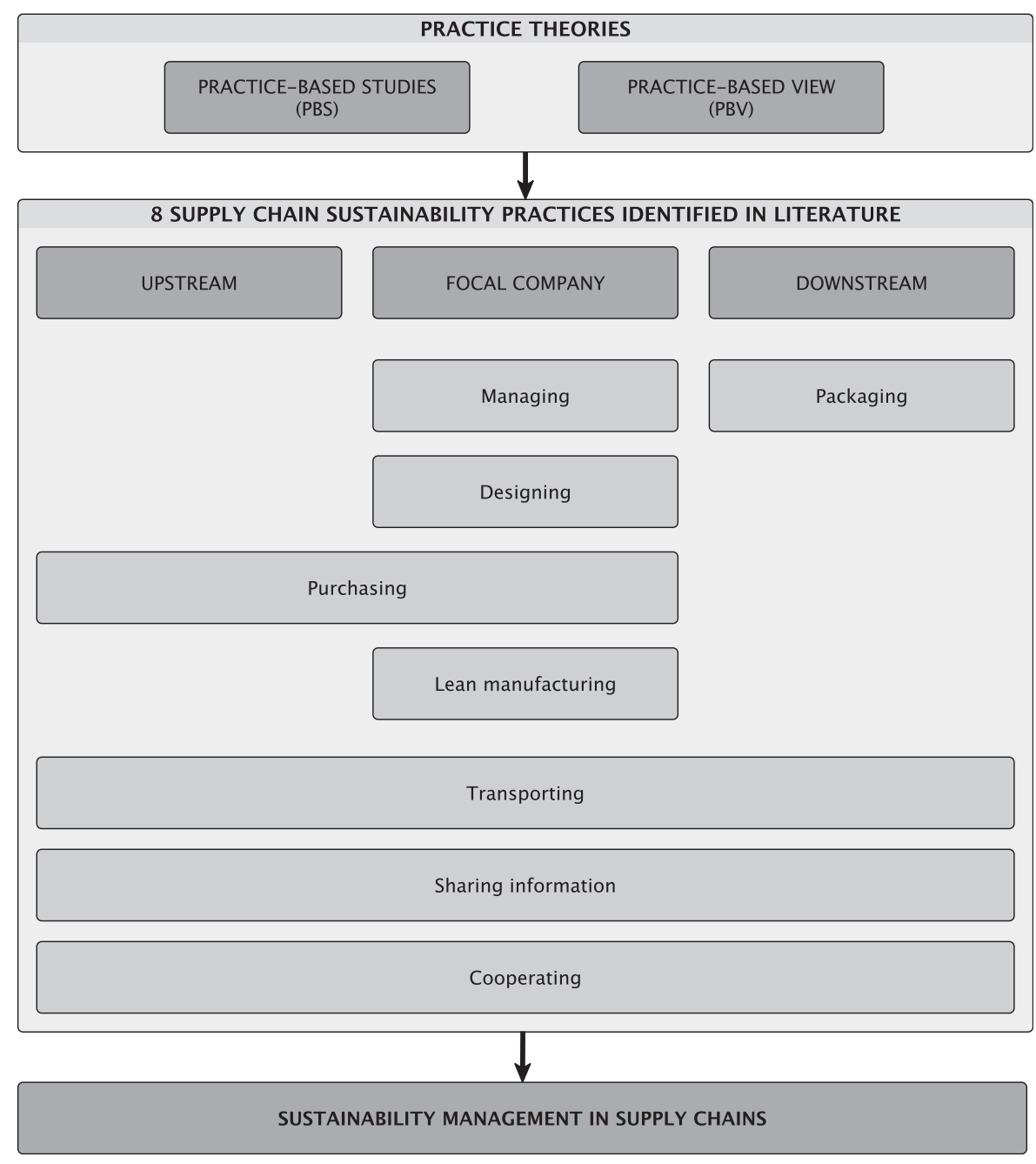

Practice theories and SCS

This leads to a criticism of current research and a request for additional studies that specifically define the meaning of sustainability, as merely referring to a focus on green logistics or social issues is too generic. If we want to advance the maturity of the field, we need to develop research studies with clear definitions and theoretical lenses, which may be facilitated by, for example, the PBV or PBS approach. In this analysis, the main theories used are: institutional theory (15 out of 232), stakeholder theory (8 out of 232), (natural) resourcebased view (9 out of 232), dynamic capabilities theory (5 out of 232) and resource dependence theory (4 out of 232), which echoes Touboulic and Walker's (2015) findings. Several papers (29) used mixed theories, where the stakeholder theory (11 out of 29) and the institutional theory (7 out of 29) are used in combination with other theories such as transaction cost theory or resource-based view. Surprisingly, a total of 129 papers (out of 232) did not mention any theory being used. This shows an a-theoretical research approach in our field, which opens opportunities for further theorization as claimed here. 


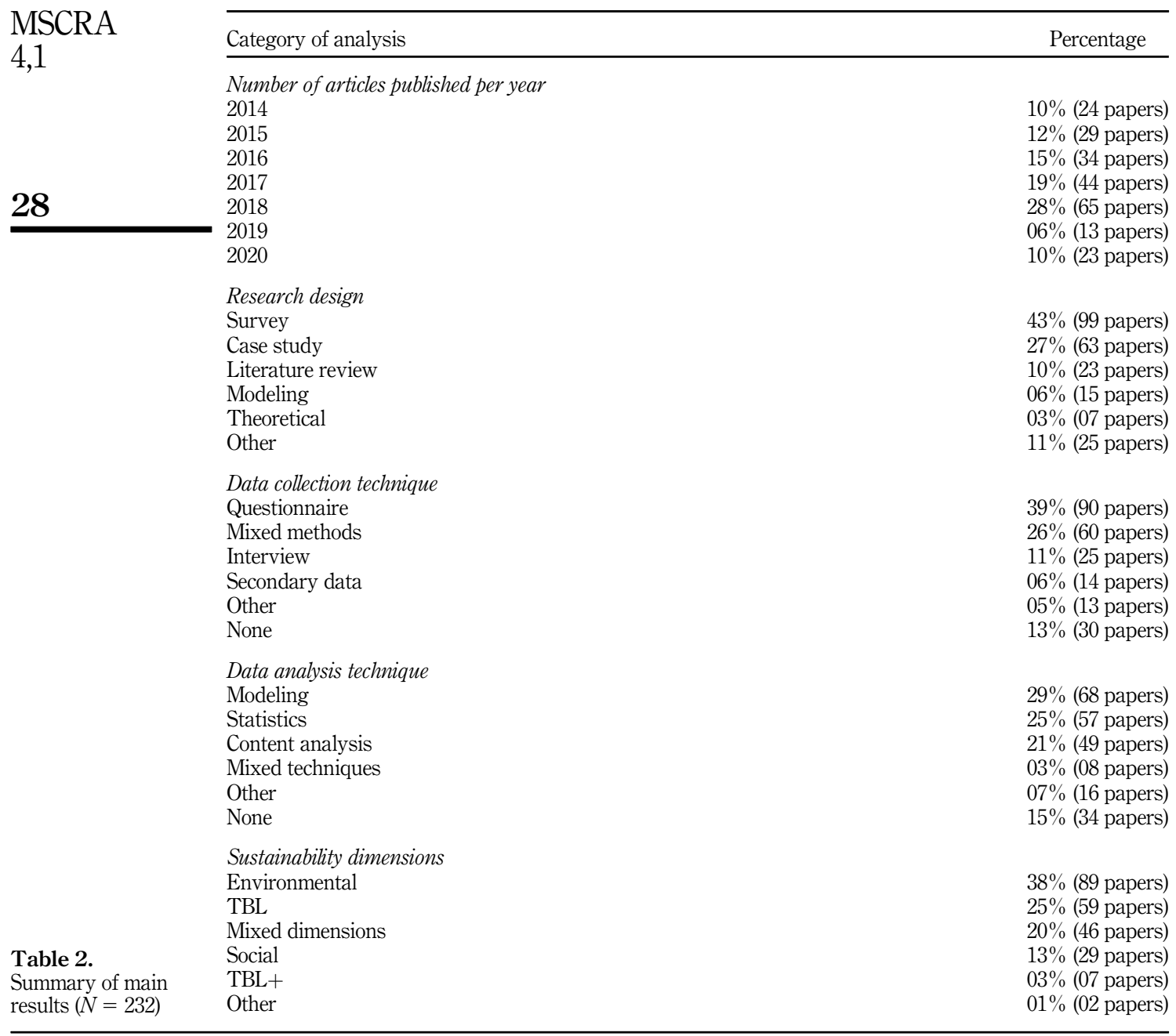

Only three papers used the PBV and two used the PBS as theoretical background. Those papers related to PBV develop their argument according to Bromiley and Rau (2014) who are responsible for connecting PBV with operations management and Carter et al. (2017) who coined the concept of Supply Chain Practice View. In addition, the definitions related to PBS are connected with what Gherardi (2009) and Nicolini (2012) have developed within organizational studies. There is still room for further connections with SCM field. Out of the definitions that were found, several papers focus on green practices or sustainable practices but few focus on social sustainability practices. However, these definitions are not grounded in any specific theory, authors mainly give examples of what they consider a "practice". Practices can be found at a management or operational level, with partners in the SC or outside the SC. At the operational level, practices are studied in the procurement department by several researchers. One paper (Paper 94) proposes to study SCS within the firm (management and operational practices), upstream and downstream. 


\subsection{The use of the "practice" concept to support sustainability management in supply chains}

To identify how the concept of practice supports SCS studies, we used both PBV and PBS as lens of analysis. At first, we recognize what a practice is based on the debate already presented in the theoretical background. For example, purchasing can be simply an activity, or it can be a practice per se, depending on which lens of analysis we are using. Therefore, when we study sustainability, sustainable purchasing constitutes an activity if we consider whether it exists by highlighting general understandings. However, the same sustainable purchasing may be a practice by means of practice theories if we consider it as a set of activities that is described by detailed information, including, among others, ordering, sourcing and buying or receiving and their connections with sustainability. The practice assumes that we are not relying on what exists using a generic perspective (e.g. tools, procedures) (Paper 03), but that we also consider why and how things happen, which needs to be informed by the knowledge and everyday habits of purchasers (who carry out the practice) embedded in such a practice. Thus, practice theories support SCS studies by better explaining what surrounds a practice.

In this sense, to provoke further use of the PBV and PBS in SCS studies, we developed in this research an inductive content analysis to demonstrate that these approaches can help further SCS research. As explained in the method section, during the reading of each of the 232 papers, we selected multiple activities related to SCM that were connected with sustainability by the authors. Using sustainable purchasing as an example, Paper 03 was the only one to address this practice with further reflection, even though practice theories are not mentioned. During the identification of SCM activities, five main activities were highlighted in terms of purchasing, namely: ordering, sourcing, buying, receiving and selecting suppliers. These activities can be defined as a practice because, when connected, they show a clear link to the concept of practice (i.e. they refer to clear activities or tasks in SCM that are connected to each other). Table 1 represents the main SCS practices found that may consider the PBV or PBS. These practices may be used by further studies to advance SCS practices studies.

Notably, even key activities (Table 1) may become practices if they are understood by their complexity and not as single activities. For example, recycling can be an activity per se, but when connected to other activities, it can be integrated into the packaging practice. The management of a SC must consider a set of multiple functions and procedures that are interconnected, so we need to observe the configuration and context of this relationship to identify the practice to be studied. Also, we need to consider any extension of this practice because we need to understand if the practice is developed only by the focal company or dyad but does not reach the sub-suppliers, which limits the applicability of sustainability. We highlight that these findings are related to our sample analysis, which does not limit the number of new practices being defined and studied on intra- and inter-organizational levels, i.e. practices may emerge according to multiple SC configurations and contexts.

In addition, we highlight that Table 1 is not intended to serve as a new guide on how to apply SCS: it is a representation of practices that were identified in our literature review. During the analysis, we also found in many articles the use of generic terms, such as "sustainable SCM practices" or "green practices" to refer to specific activities in such a way that, by simply adding these words, the relationship connects to sustainability. We claim that the SC practice, when related to sustainability, should be analyzed according to its own characteristics (Figure 2); for example, sharing information can be a sustainability practice, regardless of whether it includes all activities connected to SCS. Such a perspective was also presented by Paper 192, in which the analysis is not limit according to sustainability dimension but, instead, according to what has been done to achieve sustainability (e.g. cooperating). More than indicating the study of green practices, it is necessary to indicate what kinds of activities were used to explain why something deemed a practice is a practice and how and by whom it is performed in the SC.
Practice theories and SCS 
MSCRA

4,1

30

In addition to the main practices presented in Table 1, we identified some specific practices that contribute to SCS, but perhaps not in a direct way. For instance, Paper 226 discussed connections between bundles of human resources practices (e.g. hiring, training) and their influence on green practices. In that case, we can talk about an inter-functional perspective, since Mentzer et al. (2001) discussed the need for SCM to coordinate interactions inside the company and throughout the SC. With this issue in mind, many research opportunities emerge that involve using the PBV and/or PBS to understand SC practices connected to sustainability management. As already argued, it is possible to move from a highly instrumental perspective (i.e. studying generically) to a more critical (i.e. organic) approach that considers the singularity of each SC, which may be related either to the sector or to the configuration (e.g. global versus local).

Since theorizing and conceptualization are important for understanding a research field but are still missing from some SCM and operations research, the analysis also investigated the theoretical frameworks presented to reveal insights for future research on practices. A framework is, indeed, meant to support a better understanding of a research topic by addressing, for instance, the complexity of sustainability in SCM (Gunasekaran et al., 2004; Touboulic and Walker, 2015). Based on frameworks developed by integrating multiple elements from various sources, theories can then be developed, and research propositions can be tested (Meredith, 1993). As highlighted by Touboulic and Walker (2015, p. 38), "the future development of theories in SSCM is tightly related to its practical roots," which refers to the use that practitioners can make of it and their better understanding of SCS challenges.

Out of the 232 papers analyzed, several presented frameworks, and 14 (i.e. Paper 05, Paper 08, Paper 21, Paper 26, Paper 51, Paper 67, Paper 70, Paper 71, Paper 120, Paper 162, Paper 172, Paper 192, Paper 226, and Paper 228) enabled pinpointing where in the SC configuration sustainability practices can occur to stimulate research in and practices for SCS. Several observations can be made from this analysis. First, most papers (out of the 232 total) do not present a framework related to SCS practices. Several provide models and hypotheses to test and sometimes refer to them as frameworks, which is not the correct terminology, according to Meredith (1993). Second, several articles discuss frameworks but do not present any or only present a taxonomy. Third, articles in which the development of meaningful frameworks related to SCS practices are documented mostly emanate from the green SCM field (e.g. Paper 06, Paper 08, Paper 09, Paper 26 and Paper 32), which may be explained by the fact that green SCM is an older field of research than SCS (Fritz, 2019) and a field of research that is easier to apply to practices (contrary to research related to the social sustainability dimension, for instance).

In these papers, practices are categorized (in a generic way) using different ideas, such as "single firm practices" and "supply chain practices" (Paper 26) and "core practices" and "facilitating green practices" (Paper 08). We recognize the key role of the focal company in SCM and the need to reflect on where within the SC the sustainability practices should take place. For this reason, we represent the SCS practices identified with an upstream, focal company and downstream categorization in Figure 2, based on the various frameworks and practices identified in this literature review (see Table 1). Since the focal company is often considered the central element in the SC, we understand that "managing" the SC may emerge as a practice because it addresses a set of different activities. In such a case, by covering activities such as holistic thinking and providing sustainability-related training (Paper 09 and Paper 32), managing a SC becomes a central and successful function in many companies, a topic that needs additional attention by scholars and practitioners. This representation aims at providing a better understanding of sustainability practices in SCM based on our literature review, and we encourage researchers to further build upon it to clarify sustainability practices in SCs.

Figure 2 highlights intra- and inter-organizational practices as a representation of SCS practices upstream, within the focal company, and downstream. The practices are presented within their own representations, i.e. without the sustainable label, since we believe that 
sustainability is embedded into each activity, represented here by practices. This concept is aligned with the position of Hassini et al. (2012), who presented a framework with what they called "issues" to represent and study SCS. Through our analysis, we found eight main SCS practices, which are presented in Figure 2. These practices are related to a combination of practice-related information gleaned from the research sample; however, it is possible to develop and identify many other practices. Also, it is necessary to understand that many of our sample articles were centered on analysis of the focal company, which explains why these practices are connected in the manner they are.

\section{Discussion}

By applying practice theories lens to understand what has been examined in the SCS literature, this study clarifies the need to use the term "practice" according to its theoretical meaning (i.e. stricto sensu) rather than its very broad meaning (i.e. lato sensu) in the context of research. We observed how SCS practice studies have evolved, and we identified a set of practices through our analysis concerning SCS practices, namely: purchasing, designing, transporting, packaging, lean manufacturing, cooperating, sharing information and managing. These practices are represented in various parts of the SC configuration and context, and they are compounded by a set of activities but not limited to these eight practices found. We claim that the level of complexity moves from the activities to practices, and from the practices to SCS practices (Silva and Figueiredo, 2020). Thus, it is through the combination of these sets of practices that it is possible to reach SCS. However, this process should follow an organic approach, where every SC and every industrial sector has its own practices (Fritz and Silva, 2018) and its own stakeholders (Fritz et al., 2018) that represent its singularity.

Following such a perspective, we reinforced the debate that the often used "best practice" idea should be avoided when talking about SCS practices. Similar to what Sweeney (2012) and Touboulic and McCarthy (2019) argued, the use of "best practices" does not represent the singularity that we are presenting with an organic approach and does not clarify for whom the practice is best, i.e. no list of practices that fit all SCs exists. Since sustainability practices involve understanding how actions and meanings have been embedded in the SC configuration, we also need to consider who carries the sustainability practice. If we discuss SCs that have a significant influence in communities that are not receiving the best of these practices, it does not seem to represent what practice is appropriate for all involved. Mejías et al. (2016) explained that the sustainability introduction is necessary to promote a cultural change toward SCS, which does not depend on best practices but on what is required in the individual SC. On the part of researchers in the field, putting more effort into identifying sustainability practices and into communicating them in a way that makes these practices operationalizable (Marabelli and Vaast, 2020) will stimulate interactions between scholars and practitioners.

In terms of sustainability dimensions, the findings indicate a somewhat underexplored focus on the meaning of TBL and its applicability in studying SCS. The main sustainability dimension studied remains the environmental one, which is still the case in more recent publications as well (e.g. Khan and Yu, 2020; Shaw et al., 2021; Silva et al., 2019). To turn sustainability into action (Schrettle et al., 2014) or into practice (Silva and Figueiredo, 2017), we must critically reflect on both its applicability in the context under research and whether it is a priority, considering what has been developed. For instance, to study green practices, we need to move from the generic taken-for-granted understanding attached to such a perspective and analyze in detail what "green" means in the relevant context, why the study of green practices is a relevant research stream and who oversees it. These issues can support a better alignment than the simple use of terms like "a- 
MSCRA

4,1

critically." The same should happen with the TBL, which often is used to study sustainability but frequently receives attention in environmental issues, while economic and social issues are given a lower priority.

Pursuing sustainability should consider the context under analysis and what kind of approach fits best. This is related to the definition of theories but also to how practitioners deal with sustainability in their own daily operations. Our research demonstrates that SCS studies related to practices remain a-theoretical (cf. Touboulic and Walker, 2015), a status that requires further progress in such a context. This paper provides two new theoretical avenues regarding practice. The PBV and PBS may be used to demonstrate both theory and epistemology aligned and, at the same time, can support multiple research designs, which was also deemed a critical issue to consider when researching SCS practices. The results highlight the main use of institutional theory, stakeholder theory and the (natural) RBV; thus, these and other theories should be used in SCS studies both in following general understandings and to create strong roots for further theorization. Practice theories have the same power to strengthen a foundation on which to build theory and practical guidance (Silva and Figueiredo, 2020). Such a process will support more maturity in our field, as required by Carter et al. (2019), which will not be limited to repeating terms and expressions without reflecting on their real meaning.

Finally, we highlight that research on sustainability management in SCs needs to consider in more detail the key term "management" and recall its roots. For instance, the term "manage" can be defined as "to be responsible for controlling or organizing someone or something, especially a business or employees" or "to be in charge of and control a company, department, project, team, etc.” (Cambridge Dictionary, 2021). Managing practices, hence, refers to operations but, first and foremost, to people (Sweeney, 2012). The management of people in a SC is underexplored but can offer important insights into the key to enhancing sustainability practices, as highlighted in, for instance, procurement research, where Sancha et al. (2019) criticized the approach taken by researchers in SCS as too broad, overlooking the importance of management's relationships, not only with suppliers but also within the focal company, to develop sustainable SCs. Sancha et al. (2019) and many other researchers in procurement also highlight the importance of management and top management involvement when developing sustainable procurement activities. This opens the door to research in SCM and operations related to behavioral studies, which will eventually contribute to filling the still existing gap on the social dimension of sustainability in SCM research.

To better guide further studies using practice theories in SCS, Table 3 proposes a research agenda for further consideration in terms of developing the maturity of the field.

As we can see in Table 3, plenty of opportunities exist for further research on SCS practice. However, the fact that practices necessarily refer to human beings implies that future research on sustainability practices in SCs needs to consider the complexity of human beings regarding the factors influencing their practices. Identifying and understanding these factors will contribute to making SCs more sustainable and facilitate moving beyond simply analyzing the environmental and social impacts of production, operations or products by extending such analysis to management practices.

\section{Conclusion}

Based on our findings and discussions related to our analysis of 232 papers, we conclude that research on SCS practices is highly incipient, and the concept of practice, although relevant to deriving practical recommendations, is misused and underused. We provided two theoretical approaches that should be used to strengthen current research and practices, which can address the weakness in the connection between both fields and, at 


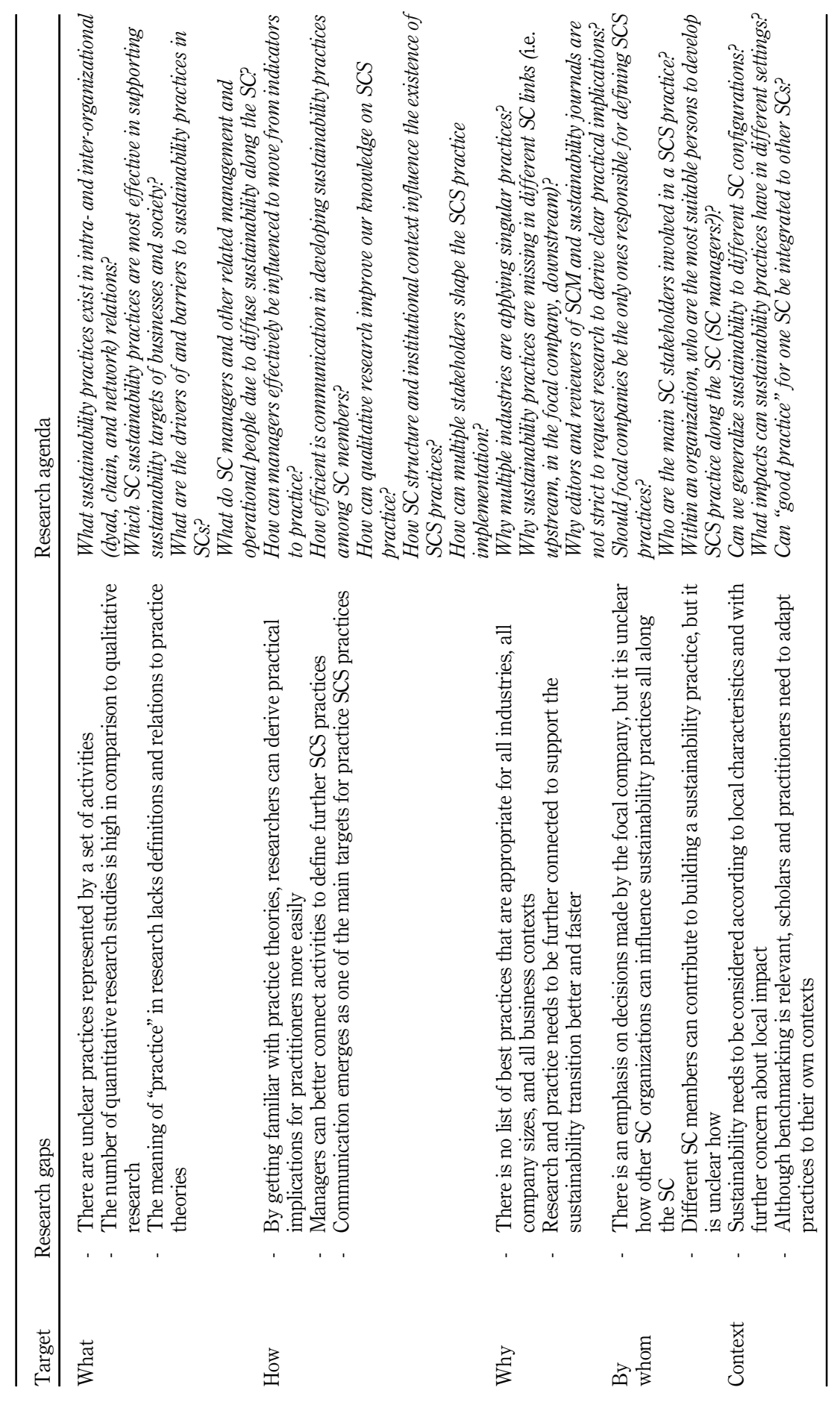

Practice theories and SCS

33

Table 3. Recommendations for further studies 
MSCRA

4,1

the same time, better align scholars and practitioners in terms of terminology and understanding of specific contexts. The use of the PBV and PBS supports the comprehension of both explicit and hidden elements inherent to SCS because the practice is not always clearly defined. Once we define it and increase its applicability, the link between theory and practice can be created.

Only a few articles from our review include a definition of what practice means and intend to develop theoretical frameworks that support the understanding of SCS practices. Hence, it is difficult to capture scholars' discourse and derive useful and operationalizable implications for practitioners. As a theoretical implication, we claim that analyzing what and who are impacted by these practices and how and why they are impacted is necessary. Indeed, researching and effectively communicating sustainability practices in SCs would support businesses and other organizations in understanding and operationalizing these practices, which requires deeper involvement by researchers to identify and interact with multiple stakeholders. Following this direction, new theoretical lenses, such as practice theories and behavioral studies, can support SCM researchers. Studies going beyond the narrow approach of SCS have the power to strengthen the maturity of the field.

This study also has several managerial implications. First, managers may increase their understanding of sustainability in their own context to develop stronger strategies. More than simply communicating/reporting sustainability, it is necessary to commit to it, which means that it should be embedded in companies' daily operations, with no risk of disappearing when faced with the first turbulence/change in the SC environment. Practices refer to concrete activities that enable stakeholders to see what is being done for sustainability in the firm and in its SC. Second, managers could use the proposed framework as a guide to clearly specify whether activities for SC sustainability are done upstream, in the firm or downstream. By having more information on sustainability practices, stakeholders can make more informed decisions (e.g. commitment of employees, investment decisions for investors, purchasing for clients) and thus the firm would gain legitimacy and build trust for its stakeholders. Overall, by sharing more on their practices for SCS, managers could complement the practices identified in Table 1 and researchers could investigate them further to extend current knowledge on Practice Theories for SCS.

The following limitations emerged during the research: (1) focus on 10 specific journals in the field, which may omit other contributions in the subject area, although this limitation does not invalidate our analysis; (2) lack of a clear definition of sustainability, which may have subjectively affected our interpretation of our article samples; and (3) the risk of omission of some relevant academic papers due to the keywords. Overall, research on sustainability practices in SCs offers a long avenue to new discoveries and empirical research that can highlight where in the SC sustainability practices occur. However, a question remains open that must be answered to increase the reflection on the maturity of the SCS field: What other unexplored theories can complement and extend current research on SCS to improve the development of theoretical and practical implications in the field?

\section{References}

Ahi, P. and Searcy, C. (2013), "A comparative literature analysis of definitions for green and sustainable supply chain management”, Journal of Cleaner Production, Vol. 52, pp. 329-341.

Ansari, Z.N. and Kant, R. (2017), "Exploring the framework development status for sustainability in supply chain management: a systematic literature synthesis and future research directions", Business Strategy and the Environment, Vol. 26 No. 7, pp. 873-892.

Antonacopoulou, E. (2015), “One more time-what is practice?”, Teoria e Prática em Administração (TPA), Vol. 5 No. 2, pp. 1-26. 
Bag, S., Gupta, S. and Kumar, S. (2021), "Industry 4.0 adoption and 10R advance manufacturing capabilities for sustainable development", International Journal of Production Economics, Vol. 231, p. 107844, doi: 10.1016/j.jpe.2020.107844.

Beske, P. and Seuring, S. (2014), "Putting sustainability into supply chain management", Supply Chain Management, Vol. 19 No. 3, pp. 322-331.

Bromiley, P. and Rau, D. (2014), "Towards a practice-based view of strategy", Strategic Management Journal, Vol. 35 No. 8, pp. 1249-1256.

Cambridge Dictionary (2021), "Managing”, available at: https://dictionary.cambridge.org/dictionary/ english/manage?q=managing (accessed 30 April 2021).

Carmagnac, L. (2021), "Expanding the boundaries of SSCM: the role of non-traditional actors", Supply Chain Forum: An International Journal, Vol. 22 No. 3, pp. 192-204.

Carter, C.R. and Easton, P.L. (2011), "Sustainable supply chain management: evolution and future directions", International Journal of Physical Distribution and Logistics Management, Vol. 41 No. 1, pp. 46-62.

Carter, C.R. and Rogers, D.S. (2008), "A framework of sustainable supply chain management: moving toward new theory", International Journal of Physical Distribution and Logistics Management, Vol. 38 No. 5, pp. 360-387.

Carter, C.R., Kosmol, T. and Kaufmann, L. (2017), “Toward a supply chain practice view”, Journal of Supply Chain Management, Vol. 53 No. 1, pp. 114-122.

Carter, C., Hatton, M., Wu, C. and Chen, X. (2019), "Sustainable supply chain management: continuing evolution and future directions", International Journal of Physical Distribution \& Logistics Management, Vol. 50 No. 1, pp. 122-146.

Dubey, R., Gunasekaran, A., Papadopoulos, T. and Wamba, S.F. (2017), "World class sustainable supply chain management: critical review and further research directions", International Journal of Logistics Management, Vol. 28 No. 2, pp. 332-362.

Elo, S. and Kyngäs, H. (2008), "The qualitative content analysis process", Journal of Advanced Nursing, Vol. 62 No. 1, pp. 107-115, doi: 10.1111/j.1365-2648.2007.04569.x.

Fink, A. (2014), Conducting Research Literature Reviews: From the Internet to Paper, 4th ed., Sage, Thousand Oaks, CA.

Flynn, B.B., Sakakibara, S. and Schroeder, R.G. (1995), "Relationship between JIT and TQM: practices and performance", Academy of Management Journal, Vol. 38 No. 5, pp. 1325-1360.

Fritz, M.M.C. (2019),“Sustainable supply chain management”, in Leal Filho, W., Azul, A., Brandli, L., Ozuyar, P. and Wall, T. (Eds), Responsible Consumption and Production, Encyclopedia of the UN Sustainable Development Goals, pp. 1-14, doi: 10.1007/978-3-319-71062-4_21-1.

Fritz, M.M.C. and Silva, M.E. (2018), "Exploring supply chain sustainability research in Latin America”, International Journal of Physical Distribution and Logistics Management, Vol. 48 No. 8, pp. 818-841.

Fritz, M.M.C., Rauter, R., Baumgartner, R.J. and Dentchev, N. (2018), "A supply chain perspective of stakeholder identification as a tool for responsible policy and decision-making", Environmental Science \& Policy, Vol. 81, pp. 63-76.

Geng, R., Mansouri, S.A. and Aktas, E. (2017), "The relationship between green supply chain management and performance: a meta-analysis of empirical evidences in Asian emerging economies", International Journal of Production Economics, Vol. 183, pp. 245-258.

Gherardi, S. (2001), "Practice-based theorizing on learning and knowing in organizations: an introduction”, Organization, Vol. 7 No. 2, pp. 211-223.

Gherardi, S. (2009), "Introduction: the critical power of the practice lens", Management Learning, Vol. 40 No. 2, pp. 115-128.

Gold, S. and Schleper, M.C. (2017), "A pathway towards true sustainability: a recognition foundation of sustainable supply chain management”, European Management Journal, Vol. 35 No. 4, pp. 425-429. 
MSCRA 4,1
Graham, S. (2018), "Antecedents to environmental supply chain strategies: the role of internal integration and environmental learning”, International Journal of Production Economics, Vol. 197, pp. 283-296.

Gunasekaran, A., Patel, C. and McGaughey, R.E. (2004), “A framework for supply chain performance measurement”, International Journal of Production Economics, Vol. 87 No. 3, pp. 333-347.

Hassini, E., Surti, C. and Searcy, C. (2012), “A literature review and a case study of sustainable supply chains with a focus on metrics”, International Journal of Production Economics, Vol. 140 No. 1, pp. 69-82.

Hitt, M.A., Carnes, C.M. and Xu, K. (2016), “A current view of resource based theory in operations management: a response to Bromiley and Rau”, Journal of Operations Management, Vol. 41 No. 10, pp. 107-109.

Hong, J., Zhang, Y. and Deng, M. (2018), "Sustainable supply chain management practices, supply chain dynamic capabilities, and enterprise performance", Journal of Cleaner Production, Vol. 172, pp. 3508-3519.

Jarzabkowski, P. (2004), "Strategy as practice: recursiveness, adaptation, and practices-in-use", Organization Studies, Vol. 25 No. 4, pp. 529-560.

Khan, S.A.R. and Yu, Z. (2020), “Assessing the eco-environmental performance: an PLS-SEM approach with practice-based view”, International Journal of Logistics Research and Applications, Vol. 26 No. 7, pp. 1-19.

Kogg, B. and Mont, O. (2012), "Environmental and social responsibility in supply chains: the practise of choice and inter-organisational management”, Ecological Economics, Vol. 83, pp. 154-163.

Kosmol, T., Reimann, F. and Kaufmann, L. (2019), "You'll never walk alone: why we need a supply chain practice view on digital procurement", Journal of Purchasing and Supply Management, Vol. 25 No. 4, p. 100553.

Kusi-Sarpong, S., Sarkis, J. and Wang, X. (2016), “Assessing green supply chain practices in the Ghanaian mining industry: a framework and evaluation”, International Journal of Production Economics, Vol. 181, pp. 325-341.

Maletič, M., Maletič, D. and Gomišček, B. (2018), "The role of contingency factors on the relationship between sustainability practices and organizational performance”, Journal of Clean Production, Vol. 171, pp. 423-433.

Mani, V. and Gunasekaran, A. (2018), "Four forces of supply chain social sustainability adoption in emerging economies”, International Journal of Production Economics, Vol. 199, pp. 150-161.

Marabelli, M. and Vaast, E. (2020), "Unveiling the relevance of academic research: a practice-based view”, Information and Organization, Vol. 30 No. 3, p. 100314.

Mejías, A.M., Paz, E. and Pardo, J.E. (2016), "Efficiency and sustainability through the best practices in the logistics social responsibility framework", International Journal of Operations and Production Management, Vol. 36 No. 2, pp. 164-199.

Mentzer, J.T., DeWitt, W., Keebler, J.S., Min, S., Nix, N.W., Smith, C.D. and Zacharia, Z.G. (2001), "Defining supply chain management", Journal of Business Logistics, Vol. 22 No. 2, pp. 1-25.

Meredith, J. (1993), "Theory building through conceptual methods", International Journal of Operations \& Production Management, Vol. 13 No. 5, pp. 3-11.

Min, S., Zacharia, Z.G. and Smith, C.D. (2019), "Defining supply chain management: in the past, present, and future”, Journal of Business Logistics, Vol. 40 No. 1, pp. 44-55.

Nicolini, D. (2012), Practice Theory, Work, and Organization: An Introduction, OUP, Oxford.

Pagell, M. and Shevchenko, A. (2014), "Why research in sustainable supply chain management should have no future”, Journal of Supply Chain Management, Vol. 50 No. 1, pp. 44-55.

Pagell, M. and Wu, Z. (2009), "Building a more complete theory of sustainable supply chain management using case studies of 10 exemplars”, Journal of Supply Chain Management, Vol. 45 No. 2, pp. 37-56. 
Rashidi, K., Noorizadeh, A., Kannan, D. and Cullinane, K. (2020), "Applying the triple bottom line in sustainable supplier selection: a meta-review of the state-of-the-art", Journal of Cleaner Production, Vol. 269, p. 122001.

Sancha, C., Wong, C.W.Y. and Gimenez, C. (2019), "Do dependent suppliers benefit from buying firms' sustainability practices?", Journal of Purchasing and Supply Management, Vol. 25 No. 4, p. 100542.

Schrettle, S., Hinz, A., Scherrer-Rathje, M. and Friedli, T. (2014), "Turning sustainability into action: explaining firms' sustainability efforts and their impact on firm performance", International Journal of Production Economics, Vol. 147, pp. 73-84.

Seuring, S. and Gold, S. (2012), "Conducting content-analysis based literature reviews in supply chain management", Supply Chain Management: An International Journal, Vol. 17 No. 5, pp. 544-555.

Seuring, S. and Müller, M. (2008), "From a literature review to a conceptual framework for sustainable supply chain management", Journal of Cleaner Production, Vol. 16 No. 15, pp. 1699-1710.

Seuring, S., Yawar, S.A., Land, A., Khalid, R.U. and Sauer, P.C. (2021), "The application of theory in literature reviews - illustrated with examples from supply chain management", International Journal of Operations and Production Management, Vol. 41 No. 1, pp. 1-20.

Shaw, S., Grant, D.B. and Mangan, J. (2021), "A supply chain practice-based view of enablers, inhibitors and benefits for environmental supply chain performance measurement", Production, Planning and Control, Vol. 32 No. 5, pp. 382-396.

Silva, M.E. and Figueiredo, M.D. (2017), "Sustainability as practice: reflections on the creation of an institutional logic”, Sustainability, Vol. 9, p. 1839.

Silva, M.E. and Figueiredo, M.D. (2020), "Practicing sustainability for responsible business in supply chains", Journal of Cleaner Production, Vol. 251, p. 119621.

Silva, M.E., Pereira, S.C. and Gold, S. (2018), "The response of the Brazilian cashew nut supply chain to natural disasters: a practice-based view", Journal of Cleaner Production, Vol. 204, pp. 660-671.

Silva, G.M., Gomes, P.J. and Sarkis, J. (2019), "The role of innovation in the implementation of green supply chain management practices", Business Strategy and the Environment, Vol. 28 No. 5, pp. 819-832.

Subramanian, N. and Gunasekaran, A. (2015), "Cleaner supply-chain management practices for twenty-first-century organizational competitiveness: practice-performance framework and research propositions", International Journal of Production Economics, Vol. 164, pp. 216-233.

Sweeney, E. (2012), "The people dimension in logistics and supply chain management: its role and importance", Supply Chain Management: Perspectives, Issues and Cases, McGraw-Hill, pp. 73-82.

Tiwari, P., Sadeghi, J.K. and Eseonu, C. (2020), "A sustainable lean production framework with a case implementation: practice-based view theory”, Journal of Cleaner Production, Vol. 277, p. 123078.

Touboulic, A. and McCarthy, L. (2019), "Collective action in SCM: a call for activist research", The International Journal of Logistics Management, Vol. 31 No. 1, pp. 3-20.

Touboulic, A. and Walker, H. (2015), "Theories in sustainable supply chain management: a structured literature review", International Journal of Physical Distribution \& Logistics Management, Vol. 45 Nos 1-2, pp. 645-658.

Tranfield, D., Denyer, D. and Smart, P. (2003), "Towards a methodology for developing evidenceinformed management knowledge by means of systematic review", British Journal of Management, Vol. 14 No. 3, pp. 207-222.

Walker, H., Miemczyk, J., Johnsen, T. and Spencer, R. (2012), "Sustainable procurement: past, present and future", Journal of Purchasing and Supply Management, Vol. 18 No. 4, pp. 201-206.

Yin, R.K. (2014), Case Study Research: Design and Methods, 5th ed., SAGE Publication, Thousand Oaks, CA. 
MSCRA

4,1

38
Zhu, Q., Liu, J. and Lai, K.-H. (2016), "Corporate social responsibility practices and performance improvement among Chinese national state-owned enterprises”, International Journal of Production Economics, Vol. 171, pp. 417-426.

\section{Appendix}

The Appendix files are available online for this article.

\section{Corresponding author}

Minelle E. Silva can be contacted at: silvam@excelia-group.com

For instructions on how to order reprints of this article, please visit our website: www.emeraldgrouppublishing.com/licensing/reprints.htm Or contact us for further details: permissions@emeraldinsight.com 